OPEN ACCESS

Edited by:

E. Christien Michael Parsons,

University of Glasgow, United Kingdom

Reviewed by:

John A. Cigliano,

Cedar Crest College, United States

Serena Lucrezi,

North-West University, South Africa

*Correspondence: Martin Thiel

thiel@ucn.cl

Specialty section:

This article was submitted to

Marine Conservation

and Sustainability,

a section of the journal

Frontiers in Marine Science

Received: 20 December 2018

Accepted: 17 April 2019

Published: 22 May 2019

Citation:

Hermoso MI, Martin VY, Stotz W, Gelcich S and Thiel M (2019) How Does the Diversity of Divers Affect the Design of Citizen Science Projects? Front. Mar. Sci. 6:239, doi: 10.3389/fmars.2019.00239

\section{How Does the Diversity of Divers Affect the Design of Citizen Science Projects?}

\author{
María I. Hermoso ${ }^{1,2}$, Victoria Y. Martin ${ }^{3}$, Wolfgang Stotz ${ }^{1}$, Stefan Gelcich ${ }^{4}$ and \\ Martin Thiel ${ }^{1,2,5 *}$
}

${ }^{1}$ Facultad Ciencias del Mar, Universidad Católica del Norte, Coquimbo, Chile, ${ }^{2}$ Millennium Nucleus Ecology and Sustainable Management of Oceanic Island (ESMOI), Coquimbo, Chile, ${ }^{3}$ Cornell Lab of Ornithology, Ithaca, NY, United States, ${ }^{4}$ Center of Applied Ecology and Sustainability, Pontificia Universidad Católica de Chile, Santiago, Chile, ${ }^{5}$ Centro de Estudios Avanzados en Zonas Áridas, Coquimbo, Chile

Divers have widely participated in citizen science (CS) projects and are one of the main groups of marine citizen scientists. However, there is little knowledge about profiles of, and incentives for potential divers to join CS projects. To date, most studies have focused on the SCUBA diving industry; nevertheless, there is a diversity of divers, not all using SCUBA, who engage in different activities during their dives. Differences in diver profiles could affect their willingness and ability to contribute to CS. In this study, we compare the diving profile, interests, preferences and motivations to participate in CS of five diver types (artisanal fishermen, recreational divers, instructors, scientific divers, and others). All divers have strong interests in participating in CS projects, with no major differences among diver types. In general, they are interested in a wide variety of themes related to CS but they prefer simple sampling protocols. Divers are motivated to participate in CS to learn about the sea and contribute to science. Some important differences among diver types were found, with artisanal fishermen having significantly more dive experience than other diver types, but less free time during their dives and limited access to some communication channels and technologies. These characteristics make them ideal partners to contribute their local ecological knowledge (LEK) to local CS projects. In contrast, recreational divers have the least experience but most free time during their dives and good access to cameras and communications channels, making them suitable partners for large-scale CS projects that do not require a high level of species knowledge. Instructors and scientific divers are well-placed to coordinate and supervise CS activities. The results confirm that divers are not all alike and specific considerations have to be taken into account to improve the contribution of each diver type to CS. The findings provide essential information for the design of different types of CS projects. By considering the relevant incentives and opportunities for diverse diver groups, marine CS projects will make efficient gains in volunteer recruitment, retention, and collaborative generation of knowledge about the marine environment.

Keywords: participatory science, subtidal, SCUBA, fishermen, recreational divers

Abbreviations: CS, citizen science; LEK, local ecological knowledge. 


\section{INTRODUCTION}

\section{Importance of Public Preferences for Participation in Citizen Science}

Citizen science (CS) is a way to generate new scientific or environmental knowledge, through the involvement of members of the public in scientific research (Dickinson et al., 2012). A variety of studies have demonstrated the usefulness of CS projects for scientific research and have also shown that CS provides other socio-ecological outcomes (Shirk et al., 2012; McKinley et al., 2017). For example, participating in CS projects enhances people's knowledge about wildlife (Brossard et al., 2005) or about science (Bonney et al., 2015), and even induces changes in environmental management (Danielsen et al., 2005, 2010). Also, changes in people's attitudes toward science or the environment have been demonstrated (Price and Lee, 2013), but are not widely investigated (Brossard et al., 2005). One socio-ecological outcome considered important in conservation practice is to engage communities in actions to mitigate environmental problems (McKinley et al., 2015). Contributing to CS efforts presents one type of action people can take. However, evidence suggests the people most interested in CS programs are those already concerned about science and the environment (Martin, 2017), meaning that CS will naturally attract a particular type of participant (pro-science or pro-environmental) rather than a broad reach across audiences with many different science/environmental attitudes. Furthermore, one of the challenges in CS projects is to recruit and retain participants. For that purpose, it is important to understand potential volunteers (Cigliano et al., 2015; Aristeidou et al., 2017) and their needs and interests in CS. In general, there is only limited knowledge about the preferences of non-participants (Martin et al., 2016b), which is nevertheless essential information to achieve a broader and more diverse participation of citizen volunteers in CS projects.

Divers are one of the main volunteer groups participating in marine CS projects (Thiel et al., 2014) and one of the most interested marine user groups (Martin et al., 2016b). However, little knowledge exists about the profiles of divers who join CS projects (Cerrano et al., 2016) and even less information is available about those who are not joining. Here we present a study of different types of divers in Chile, their background characteristics, diving experience level and their preferences for different ways of participating in marine CS.

\section{Lack of Information About the Diversity of Divers in Citizen Science Projects}

Existing evidence suggests that divers participating in CS projects have a high education level, previous interest in science and high diving experience (Arvanitidis et al., 2011; Cerrano et al., 2016; Lucrezi et al., 2018). Martin et al. (2016b) studied public interest in marine CS and found that SCUBA divers have the highest level of interest in CS among many marine user types. A recent study by Lucrezi et al. (2018) found a generally high interest among SCUBA divers to participate in CS, although only a few actively participate. Furthermore, they found a greater proportion of divers with professional certifications had participated in CS than basic divers. Although previous studies generated important knowledge for CS design (e.g., Cerrano et al., 2016; Martin et al., 2016b; Lucrezi et al., 2018), they focused primarily on the recreational SCUBA diving industry, excluding other groups who either work or recreate underwater, such as fishermen (especially those using hookah) and free divers (snorkelers). These groups possess the potential to contribute to the same CS projects that aim to engage SCUBA divers.

The diversity of divers can be differentiated by their diving technique (SCUBA divers, snorkelers, hookah, etc.) or based on their main underwater activity or profession (e.g., fishermen, military, commercial). For example, recreational divers dive for fun, adventure and to enjoy marine life (Musa et al., 2006; Edney, 2012), and may have free time for CS projects during their dives. In contrast, dive instructors dive primarily to teach or guide other divers. Given the responsibility they have, their time is limited to make and record observations during their regular dives. Some divers also extract marine resources, either professionally as artisanal fishermen (Godoy et al., 2016) or for their own consumption (Young et al., 2015). The main purpose (recreational or professional) and activities undertaken during dives is expected to strongly influence whether and how different types of divers might participate in CS.

The diver types also differ in other aspects such as demographics, experience, or interests. For example, the majority of recreational SCUBA divers are males, well educated, have high incomes, and around 5 years of diving experience (Edney, 2012; Lucrezi et al., 2013). Dive instructors usually have advanced skills but are of a similar age as recreational SCUBA divers (Watson and Pulford, 2004). Tessier et al. (2015) found recreational divers have a lower age and less experience compared to spear fishermen and other marine users. Martin et al. (2016b) found differences among stakeholder groups in their preferences to participate in CS, and while all groups in that study listed data collection as their most preferred CS activity, the groups differed in their second preference. After data collection, fishermen preferred to assist formulating research questions, divers preferred participating in data analysis, and other groups preferred to communicate the findings. Thus, it is important to take the personal and professional history of divers into account when creating CS projects to involve groups in different ways.

Diving experience can also lead to differences in divers' perception, knowledge, and attitudes about the marine environment and management (Todd et al., 2000; Thapa et al., 2005; Dearden et al., 2006; Salim et al., 2013). Recent evidence suggests that opinions or preferences about marine management issues may differ among marine users such as fishermen, recreational anglers, divers, etc. (Hattam et al., 2014; Wiener et al., 2016). Background characteristics (e.g., attitudes, knowledge, and values) held by different diver types, in combination with the demands of their diverse underwater activities, are likely to affect their willingness and ability to participate in CS. Therefore, it is important to know more about 
the differences among diver types in order to gain a better understanding of their potential and requirements to participate in CS. This is key to inform project design aimed at increasing diver participation and diversity in CS.

\section{Citizen Science Project Requirements for Divers}

Some CS projects ask for a specific profile of diver according to the tasks required to be undertaken. For example, Reef Life Survey (RLS) ${ }^{1}$ or Reef $\mathrm{Check}^{2}$ ask for recreational SCUBA divers, as their protocol requires autonomy (e.g., protocols required to be performed during the dive). Other more flexible projects are open to most marine users, such as Redmap ${ }^{3}$ or Reef Environmental Education Foundation $(\mathrm{REEF})^{4}$, which use less complex methodologies. Other projects require specific gear, for example, a dive computer to report seawater temperature (Wright et al., 2016) or a camera to take photographs that are then submitted to the CS platform, e.g., iNaturalist (Jacobs and Zipf, 2017). Some projects also require a minimum level of diving experience, for example, Reef Check or RLS (Edgar and Stuart-Smith, 2014; Roelfsema et al., 2016) or a minimum level of knowledge (verified by an exam) before volunteers can join (e.g., REEF; Wolfe and Pattengill-Semmens, 2013).

The type of CS project also influences the type of divers who participate. For example, fishers (recreational or professional) participate in initiatives about fisheries resources (Godoy et al., 2010; Suazo et al., 2013; Coll et al., 2014; Thiel et al., 2014), while SCUBA divers (recreational or instructors) participate in studies of a wider variety of target species (Schmitt et al., 1993; Edgar and Stuart-Smith, 2014) or focus on charismatic species (Theberge and Dearden, 2006).

Protocols used by recreational divers are normally based on direct observations of species during surveys, transects or opportunistic observations, while studies with fishers are frequently based on interviews or questionnaires (Thiel et al., 2014). SCUBA divers are often trained to apply their methodology before participation, while specific training sessions are rare in studies with fishermen (Schmitt et al., 1993; Arvanitidis et al., 2011). Yet these different approaches to volunteer engagement are not usually based on an understanding of the preferences different diver types have for their involvement in marine research.

Since it is clear that diver types differ in many aspects, it is reasonable to suggest they will also differ in their preferences for participation in CS. This study aims to investigate these differences to improve the design of marine CS projects with divers. Specifically, our research question is: Does diver type affect the ways in which different groups of divers might engage with CS? To answer this question we characterize different diver types to determine their needs, capacity, interest and potential to participate in CS projects, focusing specifically on their diving experience, preferences and motivations.

\footnotetext{
${ }^{1}$ www.reeflifesurvey.com

${ }^{2}$ www.reefcheck.org

${ }^{3}$ www.redmap.org.au

${ }^{4}$ www.reef.org
}

\section{Case Study Area}

Chile represents an opportunity to test the research question, as it is a country with an extended coastline and a wide variety of divers with different backgrounds who could potentially participate in CS. Despite the diversity and large number of people diving along the Chilean coast (Godoy et al., 2010; Aburto et al., 2013; Biggs et al., 2016), no previous study has used a comparative approach to determine the potential of the different diver types to engage in CS projects.

There are at least five diver types in Chile (e.g., Godoy et al., 2010, 2016; Biggs et al., 2016): (i) artisanal fishermen, who dive to collect seafood for the market and typically dive with the air supplied directly through a hose from a compressor on the boat (hookah) (Godoy et al., 2016), (ii) spear fishermen, who despite diving without air support (i.e., free dive) spend extensive time underwater and dive to great depths to capture fish recreationally (Godoy et al., 2010) or professionally (Godoy et al., 2016), (iii) recreational SCUBA divers who dive for fun (Biggs et al., 2016), (iv) dive instructors who guide or train other divers, and (v) scientific divers, who have a scientific background or who dive primarily for research. Furthermore, there are commercial or military divers, who are not our target group in this study as their diving activity precludes their potential participation in CS.

In this study, we examine the hypothesis that "divers" are a diverse group whose differences in experiences, interests, and preferences to participate in CS will vary. In order to test this hypothesis, we surveyed a diversity of divers along the Chilean coast to describe different diver types and their preferences regarding participation in CS.

\section{MATERIALS AND METHODS}

\section{Sampling}

A series of structured face-to-face interviews (Bryman, 2012) were conducted in fishermen's coves, diving centers, and universities from Arica to Chiloe between January and March in 2017 (Table 1). A convenience sampling of divers was carried out at the different sites (fishermen's coves or diving centers) where many divers were asked whether they would be willing to participate in an interview. Due to the low numbers of divers in some locations, it was necessary to use convenience sampling instead of a random sampling method. In each diving center, at least one dive master or instructor was interviewed. To find scientific divers, a "snowball sampling" method was used (Bryman, 2012), whereby scientific divers at universities (mainly in marine science faculties) were asked to help identify other scientists who dive. Before starting the interview, the interviewees were told the main goal of the study was to characterize divers in Chile and evaluate their interest in participating in CS projects. When inviting people to participate in the interview, we also highlighted they did not have to answer questions they felt uncomfortable with. In total, 229 divers were interviewed and only three people declined the interview, which represents a response rate of $99 \%$. All the people who declined were artisanal fishermen who were busy working. All interviewees in this study formally agreed to participate in the study. 
TABLE 1 | Number of divers surveyed in each location.

\begin{tabular}{|c|c|c|c|}
\hline Location & $\mathbf{N}$ & Location & $\mathbf{N}$ \\
\hline Achao & 2 & Los Molinos & 2 \\
\hline Algarrobo & 6 & Los Molles & 15 \\
\hline Ancud & 5 & Los Vilos & 1 \\
\hline Antofagasta & 18 & Mejillones & 2 \\
\hline Arica & 21 & Niebla & 7 \\
\hline Bahía Inglesa & 7 & Osorno & 4 \\
\hline Bahía Mansa & 1 & Pichidangui & 8 \\
\hline Caldera & 8 & Pisagua & 8 \\
\hline Carelmapu & 3 & Playa Blanca & 1 \\
\hline Chañaral de Aceituno & 7 & Pucatrihue & 2 \\
\hline Concepción & 14 & Puerto Montt & 5 \\
\hline Copiapó & 1 & Puerto Varas & 5 \\
\hline Coquimbo & 13 & Qellón & 4 \\
\hline Corral & 1 & Quintay & 11 \\
\hline Dichato & 5 & Tomé & 3 \\
\hline Horcon & 2 & Totoralillo (Coquimbo) & 1 \\
\hline Iquique & 12 & Valdivia & 6 \\
\hline Las Cruces & 6 & Valparaíso & 5 \\
\hline Lirquen & 3 & NA & 2 \\
\hline
\end{tabular}

\section{Survey Instrument}

The questions reported here were part of a larger survey of divers in Chile. The specific interview questions described in this study are presented in the Supplementary Data Sheet S1. The questions were designed to understand the diversity of divers assessing diving profiles, preferences and motivations for participation in a CS project. The questions were divided into five main sections: (a) demographics and contact, (b) diving profile, (c) general interest and preferences in CS, (d) protocol preferences, and (e) motivations to participate in CS.

Demographic questions (a) were developed to determine differences in age, nationality, education and gender to understand other differences within groups. For diving profile characterization (b) we asked about the diving technique used (apnea, SCUBA tank, hookah, or other), diving experience indicator (total of years diving), and about their free time during a dive. In addition, divers were asked whether they own and/or use particular accessory equipment (underwater camera and dive computer). To study general interests and preferences in CS (c) questions were subdivided in different items (general interest in participating, preferences in particular science fields, in developing specific scientific skills, studying marine biodiversity, and preferences in training aspects such as "willingness to pay for training" or "having to pass an exam"). Responses to questions in this section were measured on 5-point scales. For preferences in the protocol (d), the respondents were shown pictures of six typical protocols used in CS projects to ensure they understood what was meant by each type (Figure 1). The protocol types were scaled from less demanding (opportunistic observation) to more demanding (conduct underwater transects or experiments). To measure protocol preferences a ranking system was used to score each type of protocol. Interviewees were asked to rank these options from 1 (most preferred) to 6 (least preferred); it was possible to score 0 for protocols that the diver would never want to do. For data analysis we made a conversion from 6 (most important) to 1 (least important), and left the 0 for those protocols that divers did not want to do.

For motivation to participate in CS projects (e), respondents were asked to rank the importance of five different motivations. The motivational choices were based on the most cited motivations for volunteers (Bruyere and Rappe, 2007; Measham and Barnett, 2008; West and Pateman, 2016). Options of responses were "Learning about topics related to the sea," "Meeting people with my own interests," "Feeling that I contribute to the study of the seabed", "Having fun in the activity," and "Obtaining discounts on diving equipment"; interviewees had to rank these options from 1 (most important) to 5 (least important). Similar as above for protocols, here we inverted the scale for data analysis, so that the highest value (5) means "most important" while the lowest value (1) means "least important."

\section{Classification of Diver Types}

In the section on diver characterization (b) interviewees were asked to identify the one diver type they most identify with. The options were: artisanal fishermen, recreational divers, instructors (dive masters are included), scientific divers, spear fishermen, commercial divers, and "various" (described below). Of the 229 divers interviewed, 72 characterize themselves as artisanal fishermen, 48 as an instructor, 66 as recreational, 22 as scientific, 15 as spear fishermen, and 6 as commercial. Since the number of commercial divers and spear fishermen is low, these categories were collapsed into the group "various." Finally, there were some difficulties in the classification of scientific divers. Scientific diver is a complex concept as there are some divers who have a specific certification for scientific diving but have no professional scientific background or training (ManeyJr., and Genovese, 2000), while others are scientists but do not dive for research purposes. In this study, we defined the scientific divers as not only divers for whom their main activity during a dive is to do scientific work, but also include divers who have a scientific background. This means all divers who studied natural science at the university level are herein considered as scientific divers, irrespective of whether they classify themselves as such. The final categories evaluated include a total of 71 artisanal fishermen, 34 dive instructors, 52 recreational divers, 58 scientific divers, and 14 "various."

\section{Data Analysis}

In the present study, we used descriptive statistics to characterize divers, then tested for differences among different diver types in particular aspects (diving profile, interest, preferences, and motivation to participate in CS). Statistical analyses were undertaken with $\mathrm{R}$ studio (RStudio Team, 2016). Normal distribution of variables was tested using both the ShapiroWilk and Kolmogorov-Smirnov tests for normality. As most variables were not normally distributed, non-parametric analyses were used (Field, 2013). To detect differences among diver types Kruskal-Wallis and Mann-Whitney post hoc tests (Dytham, 2003) were performed. Effect sizes for each significant difference were calculated using Cohen's d 


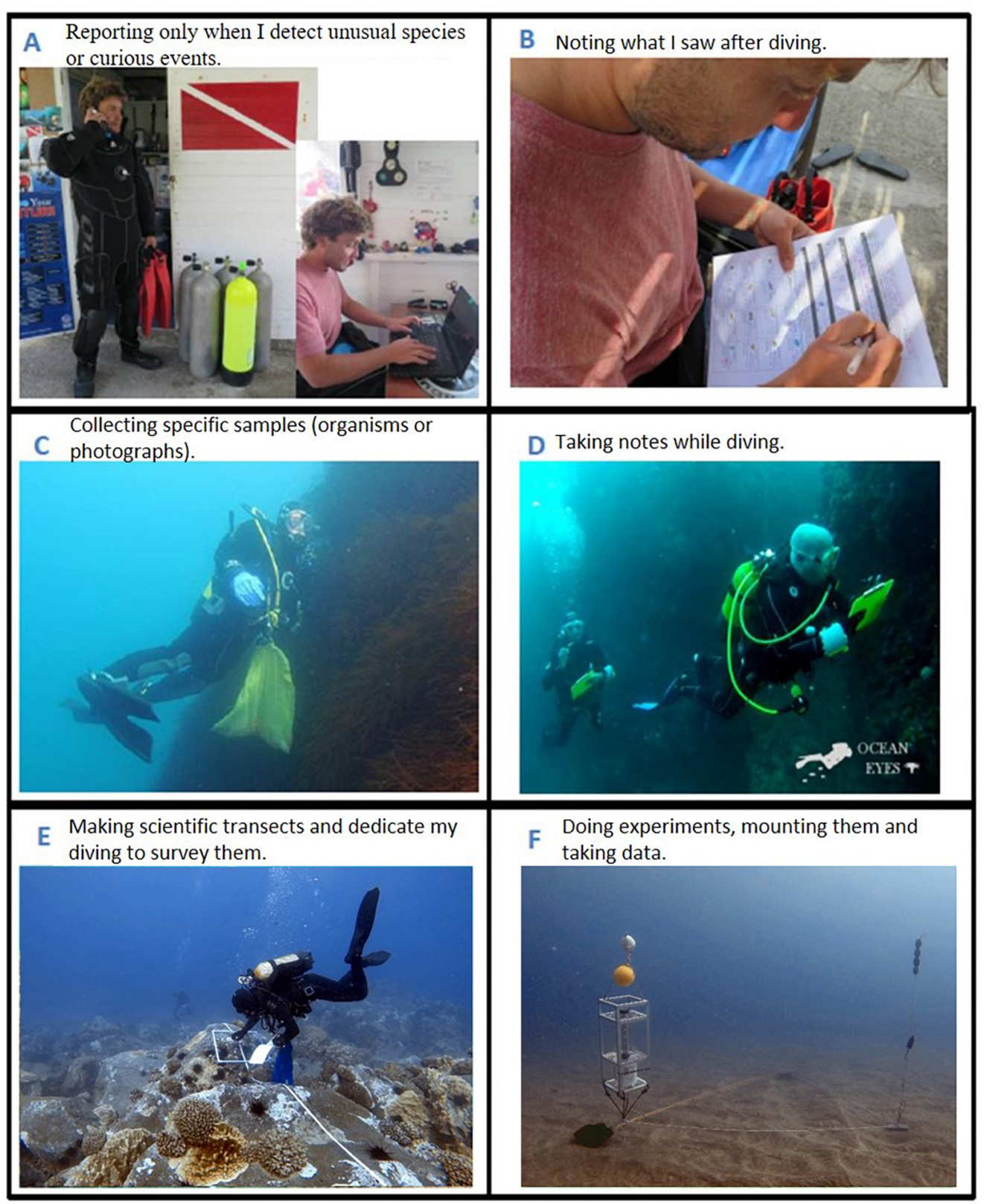

FIGURE 1 | Pictures of the six different protocols presented to divers. A written informed consent was obtained from the individual for the publication of this image. (A) Reporting only when I detect unusual species or curious events. (B) Noting what I saw after diving. (C) Collecting specific samples (organisms or photographs). (D) Taking notes while diving. (E) Making scientific transects and dedicate my diving to survey them. (F) Doing experiments, mounting them, and taking data.

(see Supplementary Table S1). A principle component analysis (PCA) was conducted to identify main variables that differentiate the diver types.

\section{Limitations of the Study}

Even though in this study great effort was made to distinguish the main types of divers in Chile, it would still be possible to further segregate some groups of divers or to subdivide them in other groups. For example, scientific divers could be subdivided into those who have a scientific background and those who are employed specifically to do scientific sampling during their dives (whether or not they have a scientific background). On the other hand, there are photographers who, in this study, were distributed mostly among the recreational and scientific divers, but could also be placed in a separate group of submarine photographers. Furthermore, spear fishermen are underrepresented in this study, but make up most of the "various" category. Although we attempted to interview similar numbers of divers for each group, some diver types were easier to identify and locate than others. For example, artisanal fishermen can 
TABLE 2 | Demographic characteristics of diver types.

\begin{tabular}{lccccc}
\hline & Artisanal & Dive & \multicolumn{2}{c}{ Scientific Recreational } \\
& fishermen instructors & divers & divers & Various \\
& $\mathbf{N = 7 1}$ & $\mathbf{N = 3 4}$ & $\mathbf{N = 5 8}$ & $\mathbf{N = 5 2}$ & $\mathbf{N = 1 4}$ \\
\hline Nationality (\%) Chilean & $100 \%$ & $94 \%$ & $93 \%$ & $90 \%$ & $100 \%$ \\
Gender (\%) men & $87 \%$ & $76 \%$ & $78 \%$ & $67 \%$ & $100 \%$ \\
Age (Average \pm SD) & $48 \pm 9$ & $34 \pm 11$ & $35 \pm 8$ & $34 \pm 9$ & $37 \pm 13$ \\
Education level (\%) & $0 \%$ & $76 \%$ & $100 \%$ & $69 \%$ & $36 \%$ \\
post-secondary & & & & &
\end{tabular}

typically be found at fishermen's coves and recreational divers are easily located at dive centers, whereas scientific divers and spear fishermen are more difficult to reach. Consequently, our survey follows a convenience sampling strategy, meaning our sample is not necessarily representative of the total population in each group. However, a truly representative sample of each diver type would be impossible since there are no national-level data available on the participation rates of each diving activity.

\section{RESULTS}

\section{Diver Characterization}

Of the 229 divers interviewed, most are from Chile (95.2\%) and male $(82.5 \%)$, with an average age of $38.8 \pm 11.3$ years (Table 2). Compared to other diver types, recreational divers and instructors have a higher proportion of women with 32.7 and $23.5 \%$, respectively. Artisanal fishermen are older than other diver types, with an average age of $47.9 \pm 9.3$ years; they also have the most basic educational level overall, generally with no postsecondary studies. Scientific divers have the highest education level, with all of them having completed post-secondary studies.

\section{Diving Profile}

The main diving mode of artisanal fishermen is diving with hookah $(95.7 \%)$, and they focus mostly on the extraction of natural resources $(91.4 \%)$. Instructors usually dive with SCUBA tanks $(94.1 \%)$, and although their activities are mainly guiding and training (76.5\%), a relatively high percentage $(23.5 \%)$ also dive for their own recreation. Not surprisingly, most of the recreational divers $(73.1 \%)$ dive with SCUBA tanks for recreation, and $19.2 \%$ also dive to take photos or videos. Scientific divers, who mainly dive with SCUBA tanks (72.4\%), primarily dive for scientific work (40\%), and almost $20 \%$ also take photos and videos. "Various" divers (64\%) marked "other activity" as their main activity during a dive and almost $30 \%$ dive for resource extraction. Most of them (64.3\%) are free divers.

Artisanal fishermen are the most experienced group with more years diving than other groups $(H=104.4 ; p<0.001)$, while recreational divers are the least experienced (Table 3 ). The individual dives of artisanal fishermen and "various" divers are typically longer (averaging more than 200 min per dive) than those of the other diver types, being shortest for instructors $(H=127.7 ; p<0.001)$. Despite the long duration, artisanal fishermen usually have no free time during their dives, while recreational divers have the most time available for potential scientific activities $(H=98.7 ; p<0.001)$. Very few $(12.7 \%)$ of the artisanal fishermen have an underwater camera or dive computer, while many of the instructors and scientific divers own and use these types of equipment (Table 3).

\section{Interest, Preferences, and Motivation to Participate in CS}

There is a generally high interest in participating in CS for all diver types (Table 4). All divers, regardless of type, express strong interests to learn about all scientific fields, knowledge, skills and all taxa (fishes, invertebrates, and seaweeds). Interest in data analysis is relatively low among all diver groups. The most preferred taxon to learn about is "fishes" and the lowest preference is for "marine mammals and seabirds." Artisanal fishermen show a relatively higher interest in mollusks and seaweeds than other diver types. All diver types express strong interest in receiving training even if they have to study and take an exam to participate in CS projects. The willingness to pay for training is relatively lower than to study or do an exam during the training, but still positive. Overall, the most preferred communication channels are e-mail and phone applications, but it is important to highlight that e-mail is not considered useful for artisanal fishermen, and neither is communication via a website. The remaining diver groups have high scores in all communication types, with the exception of letters through

TABLE 3 | Diving profile by diver type.

\begin{tabular}{|c|c|c|c|c|c|}
\hline & $\begin{array}{c}\begin{array}{c}\text { Artisanal } \\
\text { fishermen } \\
N=71\end{array}\end{array}$ & $\begin{array}{c}\text { Dive } \\
\text { instructors } \\
N=34\end{array}$ & $\begin{array}{c}\text { Scientific } \\
\text { divers } \\
N=58\end{array}$ & $\begin{array}{l}\text { Recreational } \\
\text { divers } \\
N=52\end{array}$ & $\begin{array}{l}\text { Various } \\
N=14\end{array}$ \\
\hline Dive experience (years diving average \pm SD) & $31.4 \pm 10.1 \mathrm{a}^{* * *}$ & $14.7 \pm 12.9 b^{* *}$ & $15.0 \pm 10.6 b^{* *}$ & $6.6 \pm 8.3 c^{* * *}$ & $22.1 \pm 14.7 \mathrm{ab}^{* *}$ \\
\hline Dive duration (minutes average $\pm \mathrm{SD}$ ) & $238.7 \pm 100.4 a^{* * *}$ & $40.0 \pm 18.7 c^{* * *}$ & $86.0 \pm 75.0 \mathrm{~b}^{* * *}$ & $47.3 \pm 36.8 \mathrm{bc}^{* * *}$ & $202.1 \pm 117.9 a^{* *}$ \\
\hline Free time during dives ${ }^{X}$ (Categories average \pm SD) & $1.1 \pm 0.7 \mathrm{c}^{* * *}$ & $2.4 \pm 1.5 b^{* *}$ & $2.7 \pm 1.7 b^{* *}$ & $4.4 \pm 1.2 \mathrm{a}^{* * *}$ & $2.7 \pm 2.0 \mathrm{bc}^{* *}$ \\
\hline Owns dive camera (\%) yes & $12.7 \%$ & $82.3 \%$ & $77.6 \%$ & $69.2 \%$ & $71.4 \%$ \\
\hline Owns dive computer (\%) yes & $5.6 \%$ & $79.4 \%$ & $62.1 \%$ & $38.5 \%$ & $50.0 \%$ \\
\hline
\end{tabular}

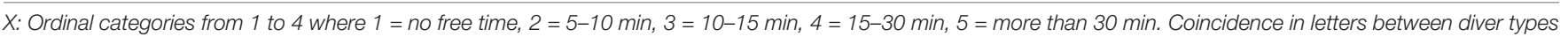

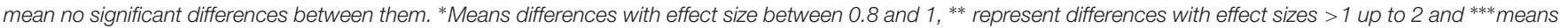

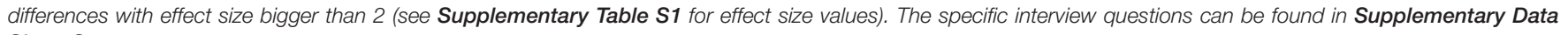
Sheet S1. 
TABLE 4 | General interest and preferences in CS for each diver type.

\begin{tabular}{|c|c|c|c|c|c|c|c|c|c|c|}
\hline & & $\begin{array}{c}\text { Total } \\
N=229\end{array}$ & & $\begin{array}{c}\text { Artisanal } \\
\text { fishermen } \\
N=71\end{array}$ & $\begin{array}{c}\text { Dive } \\
\text { instructors } \\
N=34\end{array}$ & $\begin{array}{c}\text { Scientific } \\
\text { divers } \\
N=58\end{array}$ & $\begin{array}{c}\text { Recreational } \\
\text { divers } \\
N=52\end{array}$ & $\begin{array}{l}\text { Various } \\
N=14\end{array}$ & & \\
\hline H & $p$-value & $M \pm S D$ & & $M \pm S D$ & $M \pm S D$ & $M \pm S D$ & $M \pm S D$ & $M \pm S D$ & $H$ & $p$-value \\
\hline \multicolumn{11}{|c|}{$\begin{array}{l}\text { General Interest: I } \\
\text { would be } \\
\text { interested in.... }\end{array}$} \\
\hline & & $4.4 \pm 0.9$ & Gl1. participating in CS & $4.2 \pm 1.1$ & $4.4 \pm 0.8$ & $4.5 \pm 0.7$ & $4.4 \pm 0.9$ & $4.2 \pm 0.9$ & 2.1 & 0.70 \\
\hline & & $4.3 \pm 1.0$ & $\begin{array}{l}\text { Gl2. doing exclusive dives } \\
\text { for CS }\end{array}$ & $4.2 \pm 1.1$ & $4.3 \pm 0.9$ & $4.3 \pm 1.0$ & $4.5 \pm 0.9$ & $4.1 \pm 1.3$ & 2.2 & 0.69 \\
\hline \multicolumn{11}{|c|}{$\begin{array}{l}\text { Field Knowledge: } \\
\text { I would like to be } \\
\text { trained for... }\end{array}$} \\
\hline & & $4.4 \pm 1.0$ & FK1. Species recognition & $4.6 \pm 0.8$ & $4.47 \pm 1.1$ & $4.1 \pm 1.1$ & $4.4 \pm 0.9$ & $4.4 \pm 1.0$ & 9.7 & 0.04 \\
\hline \multirow[t]{2}{*}{7.07} & $<0.05$ & $4.4 \pm 1.0$ & $\begin{array}{l}\text { FK3. Ecology (interactions } \\
\text { between species) }\end{array}$ & $4.4 \pm 0.8$ & $4.5 \pm 0.8$ & $4.3 \pm 0.9$ & $4.1 \pm 0.8$ & $4.8 \pm 0.9$ & 8.8 & 0.06 \\
\hline & & $4.2 \pm 1.0$ & $\begin{array}{l}\text { FK2. Biology (feeding and } \\
\text { reproduction) }\end{array}$ & $4.5 \pm 0.9 a$ & $4.2 \pm 0.9_{a b}$ & $4.0 \pm 1.1_{b}$ & $3.7 \pm 1.1_{b}$ & $4.6 \pm 0.9 \mathrm{ab}$ & 19.3 & $<0.01$ \\
\hline \multicolumn{11}{|c|}{$\begin{array}{l}\text { Scientific Skills. I } \\
\text { would like to be } \\
\text { coached for... }\end{array}$} \\
\hline & & $4.0 \pm 1.2$ & $\begin{array}{l}\text { SS1. Scientific sampling } \\
\text { protocols }\end{array}$ & $3.9 \pm 1.2$ & $3.6 \pm 1.3$ & $4.2 \pm 1.1$ & $3.8 \pm 1.2$ & $4.64 \pm 0.5$ & 9.9 & $<0.05$ \\
\hline \multirow[t]{2}{*}{11.6} & $<0.001$ & $3.9 \pm 1.3$ & SS2. Scientific experiments & $4.1 \pm 1.6$ & $3.5 \pm 2.1$ & $4.1 \pm 1.3$ & $3.5 \pm 1.6$ & $4.6 \pm 0.4$ & 16.7 & $<0.01$ \\
\hline & & $3.6 \pm 1.4$ & SS3. Data analysis & $3.7 \pm 1.3 \mathrm{ab}$ & $3.0 \pm 1.5_{b *}$ & $3.7 \pm 1.3_{\mathrm{ab}}$ & $3.3 \pm 1.3 \mathrm{ab}$ & $4.4 \pm 0.7 \mathrm{a}^{*}$ & 13.8 & $<0.01$ \\
\hline \multicolumn{11}{|c|}{$\begin{array}{l}\text { Biodiversity. I } \\
\text { would be } \\
\text { interested to } \\
\text { learn about... }\end{array}$} \\
\hline & & $4.4 \pm 1.0$ & B1. Fishes & $4.5 \pm 0.8 a$ & $4.5 \pm 1.0_{a b}$ & $3.9 \pm 1.2 b$ & $4.3 \pm 0.9_{\mathrm{ab}}$ & $4.7 \pm 0.8 \mathrm{ab}$ & 17.6 & $<0.01$ \\
\hline & & $4.3 \pm 1.1$ & B2. Mollusks & $4.6 \pm 0.7^{*}$ & $4.4 \pm 1.0_{a b}$ & $3.8 \pm 1.1_{\mathrm{b} *}$ & $4.1 \pm 1.0_{\mathrm{ab}}$ & $4.4 \pm 1.0_{\mathrm{ab}}$ & 25.6 & $<0.05$ \\
\hline & & $4.2 \pm 1.1$ & $\begin{array}{l}\text { B5. Crustaceans (crabs, } \\
\text { shrimps...) }\end{array}$ & $4.5 \pm 0.9_{a}$ & $4.3 \pm 1.1 \mathrm{ab}$ & $3.9 \pm 1.1 b$ & $4.1 \pm 1.1 \mathrm{ab}$ & $4.5 \pm 0.9_{a b}$ & 15.2 & $<0.01$ \\
\hline \multirow[t]{4}{*}{18.8} & $<0.001$ & $4.2 \pm 1.1$ & $\begin{array}{l}\text { B7. Marine mammals and } \\
\text { seabirds. }\end{array}$ & $3.8 \pm 1.2 b$ & $4.7 \pm 1.1_{\mathrm{a}}$ & $4.3 \pm 1.1_{a b}$ & $4.2 \pm 1.0_{\mathrm{ab}}$ & $4.6 \pm 0.7_{a b}$ & 21.9 & $<0.001$ \\
\hline & & $4.1 \pm 1.3$ & $\begin{array}{l}\text { B5. Echinoderms (sea } \\
\text { stars, sea urchins...) }\end{array}$ & $4.3 \pm 1.0$ & $4.3 \pm 1.1$ & $3.8 \pm 1.2$ & $4.0 \pm 1.2$ & $4.0 \pm 1.20$ & 11.9 & $<0.05$ \\
\hline & & $4.0 \pm 1.5$ & $\begin{array}{l}\text { B3. Cnidarian (corals, } \\
\text { jellyfish, and sea anemones) }\end{array}$ & $3.8 \pm 1.3 \mathrm{~b}$ & $4.5 \pm 0.7_{a}$ & $3.8 \pm 1.2 \mathrm{ab}$ & $4.0 \pm 1.2 \mathrm{ab}$ & $4.1 \pm 1.2_{\mathrm{ab}}$ & 11.0 & $<0.05$ \\
\hline & & $4.0 \pm 1.6$ & B6. Seaweeds & $4.4 \pm 1.1 \mathrm{a}^{*}$ & $4.2 \pm 0.7_{\mathrm{ab}}$ & $3.8 \pm 1.0_{a b}$ & $3.5 \pm 1.0_{\mathrm{b} *}$ & $4.1 \pm 0.5 \mathrm{ab}$ & 16.3 & $<0.01$ \\
\hline \multicolumn{11}{|c|}{$\begin{array}{l}\text { Participation in } \\
\text { Training: I would } \\
\text { be willing to... }\end{array}$} \\
\hline & & $4.2 \pm 1.3$ & TP2. (...) be evaluated & $4.5 \pm 1.0$ & $4.3 \pm 1.1$ & $4.1 \pm 1.2$ & $3.9 \pm 1.1$ & $4.7 \pm 0.6$ & 15.8 & $<0.01$ \\
\hline \multirow[t]{2}{*}{113.7} & $<0.001$ & $4.1 \pm 1.2$ & TP1. (...) have to study & $4.1 \pm 1.4$ & $4.2 \pm 1.3$ & $4.0 \pm 1.2$ & $4.0 \pm 1.1$ & $4.4 \pm 0.6$ & 2.9 & 0.5 \\
\hline & & $3.1 \pm 1.8$ & TP3. (...) pay & $3.0 \pm 2.2$ & $3.1 \pm 1.3$ & $2.8 \pm 2.0$ & $3.3 \pm 1.4$ & $3.3 \pm 1.6$ & 4.1 & 0.4 \\
\hline \multicolumn{11}{|c|}{$\begin{array}{l}\text { Communication: } \\
\text { It would be useful } \\
\text { to talk to } \\
\text { scientists by.... }\end{array}$} \\
\hline & & $4.0 \pm 1.3$ & C2. Phone & $4.4 \pm 1.0_{\mathrm{a}^{*}}$ & $3.5 \pm 1.3_{b}$ & $3.9 \pm 1.4 a b$ & $3.4 \pm 1.2 b^{*}$ & $4.2 \pm 1.05_{\mathrm{ab}}$ & 27.7 & $<0.01$ \\
\hline & & $4.0 \pm 1.5$ & C5. e-mail & $2.7 \pm 1.7 \mathrm{~b}^{* *}$ & $4.8 \pm 0.7_{a^{*}}$ & $4.8 \pm 0.5^{* *}$ & $4.5 \pm 0.87 \mathrm{a}^{* *}$ & $4.1 \pm 1.38 \mathrm{ab}$ & 78.2 & $<0.001$ \\
\hline \multirow[t]{4}{*}{352.5} & $<0.001$ & $4.0 \pm 1.3$ & C4. App & $3.8 \pm 1.4$ & $4.0 \pm 1.6$ & $4.0 \pm 1.29$ & $4.0 \pm 1.2$ & $4.3 \pm 0.84$ & 3.2 & 0.5 \\
\hline & & $3.8 \pm 1.4$ & C3. Web & $2.8 \pm 1.6_{b^{* *}}$ & $4.2 \pm 1.1_{\mathrm{a}^{* *}}$ & $4.3 \pm 1.0_{a^{* *}}$ & $4.3 \pm 1.0_{a^{* *}}$ & $3.9 \pm 1.14 \mathrm{ab}$ & 43.7 & $<0.001$ \\
\hline & & $3.5 \pm 1.5$ & C6. Social & $3.2 \pm 1.7_{b}$ & $4.1 \pm 1.4 \mathrm{a}$ & $3.4 \pm 1.4 a b$ & $3.4 \pm 1.47 \mathrm{ab}$ & $3.7 \pm 1.20_{a b}$ & 9.5 & $<0.05$ \\
\hline & & $1.6 \pm 1.1$ & C1. Letter & $2.3 \pm 1.4$ & $1.1 \pm 0.4$ & $1.2 \pm 0.8$ & $1.2 \pm 0.5$ & $2.2 \pm 1.31$ & 7.0 & $<0.05$ \\
\hline
\end{tabular}

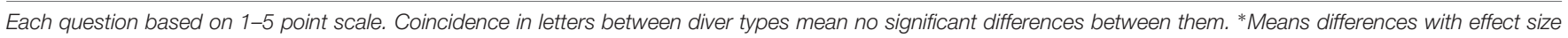

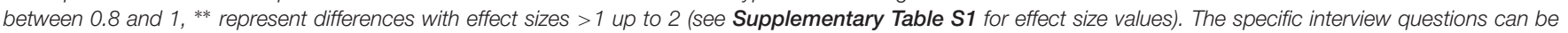
found in Supplementary Data Sheet S1. 
regular postal mail, which is the least preferred communication method for all divers.

The most preferred research protocol is "collecting samples" followed closely by "recording data after a dive" and "opportunistic observations" (Table 5). It is important to note that research protocols such as taking notes during a dive and conducting scientific transects and experiments had negative scores, e.g., are least preferred by all divers. In general, artisanal fishermen have lower scores for some protocols in which recreational and scientific divers score highest.

The main motivations to participate in CS are learning about the sea and contributing to science for all diver types (Table 6). Contributing to science is a slightly higher motivation for scientific divers. The motivation related to the enjoyment of the activity is higher for the recreational divers than for the artisanal fishermen. Social motivation (e.g., meeting people) is significantly lower for the recreational divers and dive instructors. The motivation with the lowest score is to obtain discounts for diving gear.

The PCA results highlight the main groups of divers based on all measured variables. The first two axes of the PCA explained $30.6 \%$ of the total variance (Figure 2). The PCA2 (11.8\%) separates artisanal fishermen (on the positive side of the axis) from the other diver types (on the negative side of the axis). The main variables that distinguish artisanal fishermen from the other divers are the greater number of years diving and longer dive durations (Figure 2; DP5, DP4). Most recreational divers are on the extreme negative side of the axis, with the most important variables being their extensive free time during their dives, greater access to dive cameras and computers (DP6, DP7), preference for communication by web (C3), and preference for underwater protocols (Figure 2; PP4, PP5, and PP6).

\section{DISCUSSION}

This study distinguishes among different diver types based on their main diving activity, and clarifies some differences among the groups, which could influence their willingness to engage with and contribute to CS. All groups show a high level of interest in participating in CS projects and there are no strong differences in preferred ways of participation. However, strong differences in their diving activity could help to understand their needs or requirements to participate in CS projects. This information is useful for designing strategies to recruit a greater diversity of divers to participate in CS.

\section{Characterization of Divers}

In general, demographic characteristics found in the present study are consistent with the literature. For example, a general

TABLE 5 | Preferences in different CS protocols for each diver type.

\begin{tabular}{|c|c|c|c|c|c|c|c|c|c|c|}
\hline & & $\begin{array}{c}\text { Total } \\
N=229\end{array}$ & & $\begin{array}{c}\text { Artisanal } \\
\text { fishermen } \\
N=71\end{array}$ & $\begin{array}{c}\text { Dive } \\
\text { instructors } \\
N=34\end{array}$ & $\begin{array}{c}\text { Scientific } \\
\text { divers } \\
N=58\end{array}$ & $\begin{array}{c}\text { Recreational } \\
\text { divers } \\
N=52\end{array}$ & $\begin{array}{l}\text { Various } \\
N=14\end{array}$ & & \\
\hline \multirow[t]{3}{*}{$x^{2}$} & $p$-value & $M \pm S D$ & Protocols & $M \pm S D$ & $M \pm S D$ & $M \pm S D$ & $M \pm S D$ & $M \pm S D$ & $H$ & $p$-value \\
\hline & & $4.2 \pm 1.7$ & P3. Collecting samples & $3.8 \pm 2.2$ & $4.0 \pm 1.6$ & $4.1 \pm 1.3$ & $4.7 \pm 1.3$ & $4.5 \pm 2.0$ & 9.5 & 0.05 \\
\hline & & $3.8 \pm 1.9$ & P2. Recording after a dive & $3.1 \pm 2.3_{\mathrm{b} *}$ & $3.9 \pm 1.6_{a b}$ & $4.1 \pm 1.7 \mathrm{ab}$ & $4.2 \pm 1.6{ }^{*}$ & $4.4 \pm 1.5 \mathrm{ab}$ & 9.4 & 0.05 \\
\hline \multirow[t]{4}{*}{137.6} & $<0.001$ & $3.2 \pm 2.0$ & P1. Opportunistc observations & $2.9 \pm 2.3$ & $4.1 \pm 1.8$ & $3.2 \pm 2.0$ & $3.0 \pm 1.7$ & $3.1 \pm 1.9$ & 8.0 & 0.09 \\
\hline & & $2.9 \pm 1.9$ & P4. Notes while dives & $2.1 \pm 2.2_{b}$ & $3.3 \pm 1.5 \mathrm{ab}$ & $3.3 \pm 1.5 a$ & $3.3 \pm 1.5 a$ & $2.4 \pm 1.6_{a b}$ & 14.9 & $<0.01$ \\
\hline & & $2.7 \pm 2.0$ & P5. Scientific transects & $2.4 \pm 2.3$ & $2.5 \pm 1.8$ & $3.1 \pm 1.9$ & $2.8 \pm 1.7$ & $2.3 \pm 1.9$ & 4.9 & 0.3 \\
\hline & & $2.3 \pm 1.9$ & P6. Scientific experiments & $1.5 \pm 1.8_{b}$ & $2.5 \pm 1.7 \mathrm{a}$ & $2.8 \pm 1.9 \mathrm{a}$ & $2.5 \pm 1.6 \mathrm{a}$ & $2.3 \pm 2.1_{a b}$ & 20.4 & $<0.001$ \\
\hline
\end{tabular}

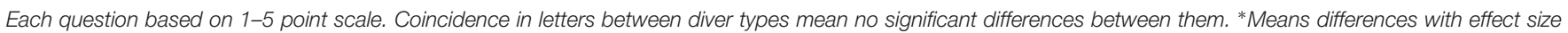
between 0.8 and 1 (see Supplementary Table S1 for effect size values). The specific interview questions can be found in Supplementary Data Sheet S1.

TABLE 6 | Motivations to participate in CS for each diver type.

\begin{tabular}{|c|c|c|c|c|c|c|c|c|c|c|}
\hline & & $\begin{array}{c}\text { Total } \\
N=229\end{array}$ & & $\begin{array}{c}\text { Artisanal } \\
\text { fishermen } \\
N=71\end{array}$ & $\begin{array}{c}\text { Dive } \\
\text { instructors } \\
N=34\end{array}$ & $\begin{array}{c}\text { Scientific } \\
\text { divers } \\
N=52\end{array}$ & $\begin{array}{c}\text { Recreational } \\
\text { divers } \\
N=58\end{array}$ & $\begin{array}{l}\text { Various } \\
N=14\end{array}$ & & \\
\hline \multirow[t]{3}{*}{$x^{2}$} & $p$-value & $M \pm S D$ & Motivation & $M \pm S D$ & $M \pm S D$ & $M \pm S D$ & $M \pm S D$ & $M \pm S D$ & $H$ & $p$-value \\
\hline & & $3.8 \pm 1.1$ & M2. Learning about sea & $4.0 \pm 0.1$ & $3.8 \pm 01.0$ & $3.8 \pm 1.1$ & $3.5 \pm 1.1$ & $3.6 \pm 1.1$ & 6.7 & 0.1 \\
\hline & & $3.6 \pm 1.3$ & M3. Contribute to science & $3.4 \pm 1.3_{b}$ & $3.7 \pm 1.1_{\mathrm{ab}}$ & $3.3 \pm 1.3_{b}$ & $4.1 \pm 1.0_{a}$ & $3.6 \pm 1.5_{\mathrm{ab}}$ & 13.2 & $<0.05$ \\
\hline \multirow[t]{3}{*}{219.6} & $<0.001$ & $2.7 \pm 1.3$ & M1. For fun & $2.3 \pm 1.3_{b}$ & $2.8 \pm 1.3_{\mathrm{ab}}$ & $3.3 \pm 1.4 a$ & $2.6 \pm 1.2 \mathrm{ab}$ & $2.2 \pm 1.4 \mathrm{ab}$ & 18.0 & $<0.01$ \\
\hline & & $2.7 \pm 1.1$ & M4. Meeting people & $2.9 \pm 1.1_{a b}$ & $2.3 \pm 1.0_{\mathrm{b} * *}$ & $2.4 \pm 0.9_{\mathrm{b} * *}$ & $2.8 \pm 1.1_{a b}$ & $3.3 \pm 0.7_{a^{* *}}$ & 15.5 & $<0.05$ \\
\hline & & $2.1 \pm 1.6$ & M5. Obtaining discounts & $2.3 \pm 1.6$ & $2.2 \pm 1.7$ & $2.0 \pm 1.5$ & $1.9 \pm 1.5$ & $2.3 \pm 1.6$ & 3.1 & 0.5 \\
\hline
\end{tabular}

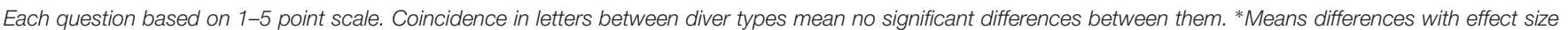

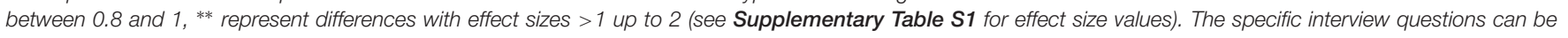
found in Supplementary Data Sheet S1. 


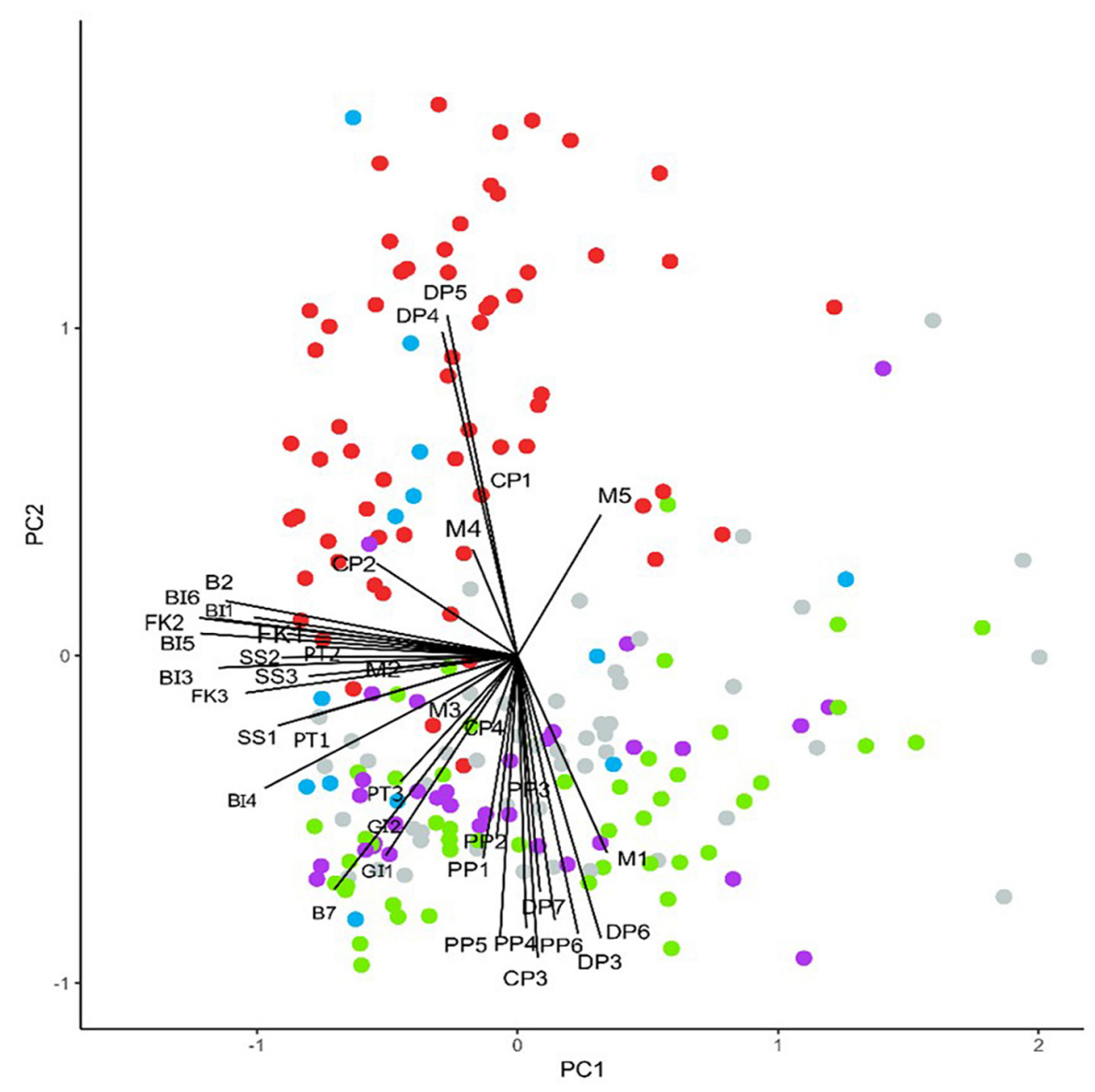

\begin{tabular}{|l|}
\hline LEGEND \\
Diver type \\
Artisanal fishermen \\
Dive instructors \\
Scientific divers \\
Recreational divers \\
Various \\
Codes \\
DP - Diving profile \\
DP3 - Free time during dives \\
DP4 - Dive experience \\
DP5 - Dive duration \\
DP6 - Owns dive camcra \\
DP7 - Owns dive computer \\
GI - General interest \\
FK - Field knowledge \\
SS - Scientific skills \\
BI - Biodiversity interests \\
PT - Participation in training \\
CP - Communication preferences \\
CP3 - Web plataform \\
PP - Protocol preferences \\
PP4 - Taking notes during divers \\
PP5 - Doing scientific transects \\
PP6 - Doing experimental studics \\
M - Motivations \\
* for further details of other codes, \\
see Supplement I \\
\hline
\end{tabular}

FIGURE 2 | PCA showing diving profile, interest, and preferences in CS by diver type.

$70 / 30$ ratio of male/female divers is frequently found in the literature for SCUBA divers (Lucrezi et al., 2018), and the much higher proportion of males among the artisanal fishermen is consistent with that found in other studies with fishermen (Thiel et al., 2014; de Andrade and de Oliveira Soares, 2017; de Juan et al., 2017). The average age for fishermen and instructors in this study is similar to that found in Curacao and Bonaire (Johnson and Jackson, 2015), and for recreational divers it is similar to other studies in diverse locations such as Spain, Malaysia, and Micronesia (Mundet and Ribera, 2001; Musa et al., 2006; Edney, 2012). A high educational level is also characteristic of SCUBA divers (Musa et al., 2006; Freiwald et al., 2018; Lucrezi et al., 2018), while a comparatively basic educational level has been previously documented for artisanal fishermen (Grant and Berkes, 2007; Carrasco and Menéndez, 2013; de Andrade and de Oliveira Soares, 2017).

Differences in diving experience among groups have also been reported before. For example, recreational divers are generally less experienced than other divers or fishermen (Johnson and Jackson, 2015; Tessier et al., 2015). The number of years diving in recreational divers ( $6.6 \pm 8$ years) is similar to that found in Australia ( $7 \pm 9$ years; Hammerton, 2017), Miami (median 6.5; Stang and Wiener, 1970) or Micronesia where most of the divers have been diving for less than 15 years (Edney, 2012), and slightly lower than in Barbados (10.7 \pm 9.6; Kirkbride-Smith et al., 2013). Our study simplifies diving experience using only the number of years of diving experience, which might be a limited way to characterize the complexity of "experience." Other studies include more variables, such as total dives logged or number of diving certifications (e.g., Lucrezi et al., 2013; Cerrano et al., 2016). However, most artisanal fishermen have only one single dive license (the one they are legally required to have), and they usually do not keep a dive log, yet of all diver types, they spend the greatest amount of time underwater, accumulating extensive experience. Thus, while other variables might be useful, within the Chilean context the total years diving is considered the most useful indicator for diving experience.

Dive duration in our study for recreational divers $(47.3 \pm 36.8 \mathrm{~min})$ is slightly lower than reported for Philippines (56 $\pm 6.4 \mathrm{~min}$; Vianna et al., 2014), Florida (54.2 min; Camp and Fraser, 2012), or in the Red Sea at Sharm el Sheik (48.6 min; Branchini et al., 2015), and more similar to that found in the Mediterranean Sea (44-48 min; Terrón-Sigler et al., 2016). The shorter dive time in our study might be explained by the comparatively low water temperature in the Humboldt Current System (Thiel et al., 2007), which naturally reduces the amount 
of time divers are able to spend in the water (Stang and Wiener, 1970). No previous study has investigated the amount of free time during dives, which is important information to take into account when developing CS projects that rely on volunteers.

\section{Motivations and Preferences to Participate in CS}

The results of this study show that contributing to science and to personal learning are typical motivations to participate in CS projects, irrespective of the type of diver. Similar motivations have been reported in other studies with divers (Cerrano et al., 2016; Martin et al., 2016a; Lucrezi et al., 2018). Meeting people is of less importance for instructors and recreational divers than for other diver types. Both diver types are involved in diving as a social activity, with meeting people being an inherent part of the activity (MacCarthy et al., 2006; Dimmock, 2009), which is why they might place less emphasis on this aspect. Understanding motivations is useful for proposing incentives strategies for CS projects to engage divers. Based on our results, it is important to all diver types that CS projects have good outreach instruments to share the scientific results. Feedback to participants has also been found to be an important component of public engagement in marine CS (Martin et al., 2016b).

The preferences divers expressed for CS protocols indicate that divers are not equally interested in performing the different tasks during their dives. In general, more complex tasks in CS projects tend to attract fewer volunteers or limit their participation (Bonney et al., 2009; Franzoni and Sauermann, 2014). Many potential volunteers think they need more knowledge or skills to contribute to CS projects, which might discourage them from participating (Martin et al., 2016a; Lucrezi et al., 2018). Even though some artisanal fishermen mentioned that they have experience in helping professional scientists with underwater transects, they were the group with the lowest interest in using transects. This could be explained by the very limited free time during their dives. Therefore, one recommendation for initiating a project in a location where divers have limited CS experience is to start with less complex protocols, even when some divers have extensive diving experience.

Divers in this study expressed a strong interest in participating in CS projects. This finding is similar to other studies of divers (Martin et al., 2016b; Lucrezi et al., 2018). Most CS projects with divers are in the field of biology and ecology (Thiel et al., 2014) and their interest in these two fields is reflected in our results. Divers, in general, are less interested in participating in data analysis, even though the average scores were still positive. Martin et al. (2016b) found that divers are more interested in data analysis than other marine users, which is likely due to the high science education level of the divers surveyed in that study. On the other hand, artisanal fishermen are very interested in research on mollusks and seaweeds, which appears reasonable since these organisms are one of the main target resources they harvest (Aburto et al., 2013). The participation of fishermen in CS has been related to their fishing target species (e.g., Obura, 2001; Le Fur et al., 2011), but there are also successful experiences with other taxa (e.g., Aswani and Lauer, 2006; Azzurro and Bariche,
2017), which herein is reflected in their wide interest in diverse taxonomic groups.

Communication channels in CS are very important to maintain volunteers' engagement with CS projects (Cooper et al., 2007; Tulloch et al., 2013). All diver types in this study find electronic communication useful with the exception of artisanal fishermen, for whom e-mail and the internet is not a useful method. Artisanal fishermen in Chile usually live in remote fishing villages and have restricted access to the internet (Gallardo et al., 2011), yet our study found they have positive scores in other communication channels that require internet access (such as mobile applications and social networks).

\section{The Diversity of Divers and Designing CS Projects}

Different diver types have similar preferences and motivations to participate in CS, but there are important differences in their profile that could affect their participation in CS projects. For example, the differences in education level could influence their decision to participate, since a low level of education has been reported as a barrier to CS projects (Savio et al., 2017) and can affect data quality (Delaney et al., 2008). Our findings show that artisanal fishermen, despite their comparatively basic science literacy, have a high level of diving experience. This means they will likely have better diving skills and more knowledge about species and ecosystem changes (Macdonald et al., 2014), which should positively affect data quality. They are familiar with local species and spend long hours underwater, making them important collaborators for studying changes over time, by contributing their deep local ecological knowledge (LEK) (Drew, 2005; Stephenson et al., 2016). Furthermore, they usually live near the shore, and observe their local marine habitats continuously, including during unfavorable weather conditions, such as winter seasons or storm events. These characteristics make fishermen ideal partners in a monitoring system that aims at detecting shifts in the ecosystem, including changing species abundances or arrival of exotic species. Their dependence on marine resources (de Juan et al., 2017) and their extensive knowledge about the marine environment means they could contribute to new, relevant research questions. However, to facilitate their participation in a CS project, it is important to keep in mind that fishermen prefer face-to-face conversations to share their experiences rather than responding to anonymous surveys or completing complex protocols (Obura et al., 2002; Thiel et al., 2014).

Recreational divers on the other hand are highly educated (Martin et al., 2016b; Freiwald et al., 2018) and have most of their dive time available for making observations or scientific activities, but have less diving experience. Some CS projects require intensive activities during a dive, such as conducting scientific transects (Edgar et al., 2014; Roelfsema et al., 2016). For these kinds of projects, a minimum diving experience and training is required (Edgar et al., 2014; Roelfsema et al., 2016), which reduces the pool of potential volunteers. Furthermore, transect protocols are incompatible with most dives conducted by a diving center. To overcome this concern, some projects 


\begin{tabular}{|c|c|c|c|c|c|c|}
\hline & & Artisanal fishermen & Dive instructors & Scientific divers & Recreational divers & Various \\
\hline \multirow{3}{*}{ 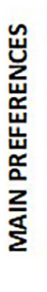 } & Communication & (6) APPe, App and social Media & & e-mail, Web, Phone & App and Social Media & \\
\hline & Protocols & & \multicolumn{4}{|c|}{ Collecting Samples, recording after a dive and opportunistic obs ervations } \\
\hline & Motivations & \multicolumn{5}{|c|}{ Learning about the sea and feeling they are contributing to science } \\
\hline \multirow{8}{*}{ 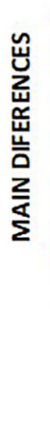 } & Main activity & Resources extraction & Guide/Training & Scientific Survey & Recreation & Other activity \\
\hline & Diving Mode & Hooka & Scuba Tank & Scuba Tank & Scuba Tank & Freedivers \\
\hline & Diving Experience & + & • & • & - & + \\
\hline & Diving Duration & + & - & $\cdot$ & - & + \\
\hline & Free time during a dive & - & $\cdot$ & $\cdot$ & + & - \\
\hline & Technological equipment & - & + & $\cdot$ & - & $\cdot$ \\
\hline & Comunication facilities & - & + & + & + & + \\
\hline & MAIN RECOMENDATIONS & $\begin{array}{l}\text { More local projects, face- } \\
\text { to-face surveys, TEK and } \\
\text { changes reports. }\end{array}$ & $\begin{array}{l}\text { Coordinators, basic task } \\
\text { during the dives, } \\
\text { oportunistic reports } \\
\text { with pictures. }\end{array}$ & $\begin{array}{l}\text { Supervisors, CS surveys } \\
\text { validation, more } \\
\text { complex protocols. }\end{array}$ & $\begin{array}{l}\text { Long spatio-temporal } \\
\text { scale projects, with } \\
\text { good training and } \\
\text { validation system. }\end{array}$ & $\begin{array}{l}\text { Due to the low number } \\
\text { of divers studied we can } \\
\text { not extract a solid } \\
\text { conclusion. }\end{array}$ \\
\hline
\end{tabular}

FIGURE 3 | Main preferences and differences between diver types and recommendations for each, based on the results of the present study.

have developed simplified data recording protocols (Bonney et al., 2009; Edgar and Stuart-Smith, 2009; Freitag et al., 2016; Vermeiren et al., 2016), for example, those based on opportunistic observations (Huveneers et al., 2009; Couturier et al., 2015; Ward-Paige et al., 2018).

Some CS projects with divers are using photographs, e.g., iNaturalist (Fourcade, 2016) or REDMAP (Pecl et al., 2014). This could represent a barrier for artisanal fishermen as they generally do not have an underwater camera, while dive instructors, on the other hand, would fit very well with this type of project as their dives are usually long, and most of them own cameras. Furthermore, they are familiar with (and often own) dive computers, which provide more accurate data about the physical conditions during the dives (such as time, depth, temperature; Wright et al., 2016).

Based on the above considerations it is possible to express several simple recommendations for CS projects for all types of divers (Figure 3). We recommend artisanal fishermen for more local projects where it is possible to engage in face-toface interactions, contractual, or co-created CS projects (Shirk et al., 2012). This will be particularly valuable for projects aiming to detect ecosystem changes. Recreational divers, who can be contacted via social media or other online communication tools, might be best engaged in large-scale, contributory projects (Shirk et al., 2012). However, due to their low diving experience and irregular contact with marine ecosystems, it will be very

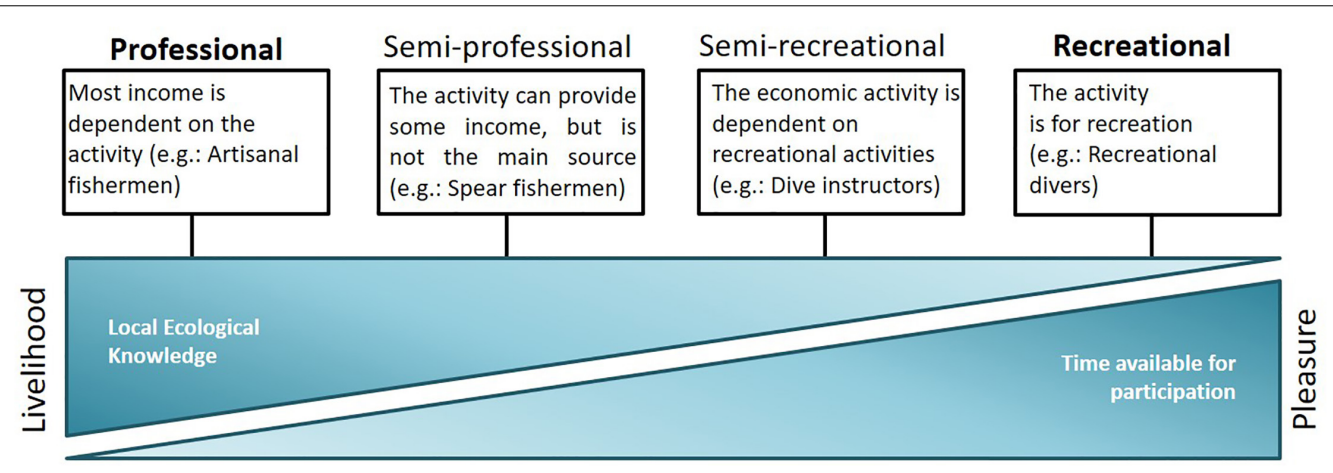

FIGURE 4 | Differences between potential volunteers in CS based on their economic dependence on the activity related to a CS project. 
important to create good validation systems for these CS projects. If long-term engagement is achieved with recreational divers, they may improve their skills over time. For this reason, recreational diver projects should consider starting out with more simple tasks (e.g., reporting photographic records) and advancing toward more complex tasks (including specific samplings or transect protocols). At the same time, considering the extensive diving experience of the instructors, their general interest in CS and their direct interaction with recreational divers (Lucrezi et al., 2018), we recommend them as a strategic figure in CS projects with recreational divers. In addition, scientific divers would be appropriate to generate trust among other diver types, explain protocols and take part in a data validation system. For "various" divers, due to our lack of data, we propose to develop more studies that focus on spear fishermen, because this group in particular can help to contribute to the documentation of long-term shifts in resource traits (Godoy et al., 2010; Young et al., 2015).

\section{CONCLUSION}

The results highlight the importance of knowing the characteristics of different diver types to determine the best way of recruiting them to CS projects. We found all diver types have a generally high interest in CS, along with similar preferences for how they participate. However, there are some important differences in their diving profile that are likely to determine how they will and can participate in CS. The strongest contrast became evident between artisanal fishermen and recreational divers, for whom the nature of their underwater activity and equipment has a direct bearing on their capability to record observations for CS. Thus, categorizing potential volunteers as professionals (who contribute to a project during their professional activity) and recreational (who contribute to a project from their hobby activity) could be useful to understand differences in volunteer preferences and requirements to participate in CS projects. In general, it is expected that professional volunteers have a high potential to collect valuable information about the environment based on their LEK, but they have specific requirements due to their lack of free time during their professional activities. In contrast, recreational volunteers will have another specific potential (more time to participate) but may have much more limited ecological knowledge, meaning there is a limit to the complexity that should be involved in the data collection process for this group. The current results on different diver types may extend to different types of marine users (e.g., cargo shipping, fish trawlers, coast guards, or recreational captains) or beach users (e.g., lifeguards or tourist visitors). Knowing the interests of potential volunteers and what is required to engage them will improve the design of CS projects and effective recruitment and retention of volunteers. Identifying and grouping potential volunteers with similar preferences and requirements will help to design more engaging projects (Figure 4) for other groups of volunteers participating in marine (or even terrestrial) CS.

\section{ETHICS STATEMENT}

This study a carried out in accordance with the recommendations of "Reglamento del Comité Ético Científico, Comité Ético Científico de la Sede de Coquimbo de la Universidad Católica del Norte," with written informed consent from all subjects. All subjects gave written informed consent in accordance with the Declaration of Helsinki. The protocol was approved by the "Comité Ético Científico de la Sede de Coquimbo de la Universidad Católica del Norte under resolution N²017-6”.

\section{AUTHOR CONTRIBUTIONS}

$\mathrm{MH}, \mathrm{MT}$, and WS contributed conception and design of the study. MH, MT, WS, and SG performed the methodology. $\mathrm{MH}$ organized the database and wrote the first draft of the manuscript. $\mathrm{MH}$ and VM performed the statistical analysis. VM, MT, WS, and SG reviewed and edited the manuscript. All authors contributed to manuscript revision, read, and approved the submitted version.

\section{FUNDING}

The project leading to this manuscript has received funding from the Fondo Nacional de Desarrollo Científico y Tecnológico from Chile $\mathrm{N}^{\circ}$ 1161383. $\mathrm{MH}$ has a fellowship from the Comisión Nacional de Ciencia y Tecnología (CONICYT-PCHA/Doctorado Nacional/2015-21151421) which permit her dedication to the presented study.

\section{ACKNOWLEDGMENTS}

We wish to thank all the divers who participated in this study and the diving clubs and fishing coves who helped us to promote the survey. We would also like to thank the reviewers whose comments have improved this manuscript substantially. M. Hermoso holds a fellowship from the Comisión Nacional de Ciencia y Tecnología (CONICYT-PCHA/ Doctorado Nacional/2015-21151421). The survey was financed by FONDECYT 1161383 to MT and WS. This study was approved by the Ethics Committee of the Faculty of Medicine of Universidad Católica del Norte under resolution F.M. $\mathrm{N}^{\circ}$ 2017-6. The Cornell Lab of Ornithology provided support for $\mathrm{VM}$ and $\mathrm{MH}$ during the preparation of the manuscript.

\section{SUPPLEMENTARY MATERIAL}

The Supplementary Material for this article can be found online at: https://www.frontiersin.org/articles/10.3389/fmars. 2019.00239/full\#supplementary-material 


\section{REFERENCES}

Aburto, J., Gallardo, G., Stotz, W., Cerda, C., Mondaca-Schachermayer, C., and Vera, K. (2013). Territorial user rights for artisanal fisheries in Chile - intended and unintended outcomes. Ocean. Coast. Manag. 71, 284-295. doi: 10.1016/j. ocecoaman.2012.09.015

Aristeidou, M., Scanlon, E., and Sharples, M. (2017). Profiles of engagement in online communities of citizen science participation. Comput. Human Behav. 74, 246-256. doi: 10.1016/j.chb.2017. 04.044

Arvanitidis, C., Faulwetter, S., Chatzigeorgiou, G., Penev, L., Bánki, O., Dailianis, T., et al. (2011). Engaging the broader community in biodiversity research?: the concept of the COMBER pilot project for divers in ViBRANT. Zookeys 150, 211-229. doi: 10.3897/zookeys.150.2149

Aswani, S., and Lauer, M. (2006). Incorporating fishermen's local knowledge and behavior into geographical information Systems (giS) for designing marine protected areas in Oceania. Hum. Organ. 65, 81-102. doi: 10.17730/humo.65.1.4y2q0vhe4l30 n0uj

Azzurro, E., and Bariche, M. (2017). Local knowledge and awareness on the incipient lionfish invasion in the eastern Mediterranean Sea. Mar. Freshw. Res. 68, 1950-1954.

Biggs, D., Amar, F., Valdebenito, A., and Gelcich, S. (2016). Potential synergies between nature-based tourism and sustainable use of marine resources: insights from dive tourism in territorial user rights for fisheries in Chile. PLoS One 11:e0148862. doi: 10.1371/journal.pone.014 8862

Bonney, R., Cooper, C. B., Dickinson, J., Kelling, S., Phillips, T., Rosenberg, K. V., et al. (2009). Citizen science: a developing tool for expanding science knowledge and scientific literacy. Bioscience 59, 977-984. doi: 10.1525/bio.2009.59.11.9

Bonney, R., Phillips, T. B., Ballard, H. L., and Enck, J. W. (2015). Can citizen science enhance public understanding of science? Public Underst. Sci. 25, 2-16. doi: $10.1177 / 0963662515607406$

Branchini, S., Pensa, F., Neri, P., Tonucci, B. M., Mattielli, L., Collavo, A., et al. (2015). Using a citizen science program to monitor coral reef biodiversity through space and time. Biodivers. Conserv. 24, 319-336. doi: 10.1007/s10531014-0810-7

Brossard, D., Lewenstein, B., and Bonney, R. E. (2005). Scientific knowledge and attitude change?: the impact of a citizen science project. Int. J. Sci. Educ. 27, 1099-1121. doi: 10.3390/ani8110190

Bruyere, B., and Rappe, S. (2007). Identifying the motivations of environmental volunteers. J. Environ. Plan. Manag. 50, 503-516. doi: 10.1080/09640560701402034

Bryman, A. (2012). Social Research Methods, 4th Edn. Oxford: Oxford University Press.

Camp, E., and Fraser, D. (2012). Influence of conservation education dive briefings as a management tool on the timing and nature of recreational SCUBA diving impacts on coral reefs. Ocean Coast. Manag. 61, 30-37. doi: 10.1016/ j.ocecoaman.2012.02.002

Carrasco, P. F., and Menéndez, E. P. (2013). Chilean caletas, more than artisan fishing villages. J. Coast. Res. 65, 939-944. doi: 10.2112/si65-159.1

Cerrano, C., Milanese, M., and Ponti, M. (2016). Diving for science - science for diving: volunteer SCUBA divers support science and conservation in the Mediterranean Sea. Aquat. Conserv. Mar. Freshw. Ecosyst. 27, 303-323. doi: $10.1002 /$ aqc. 2663

Cigliano, J. A., Meyer, R., Ballard, H. L., Freitag, A., Phillips, T. B., and Wasser, A. (2015). Making marine and coastal citizen science matter. Ocean Coast. Manag. 115, 77-87. doi: 10.1016/j.ocecoaman.2015.06.012

Coll, M., Carreras, M., Ciércoles, C., Cornax, M. J., Gorelli, G., Morote, E., et al. (2014). Assessing fishing and marine biodiversity changes using fishers' perceptions: the spanish Mediterranean and Gulf of Cadiz case study. PLoS One 9:15.

Cooper, C. B., Dickinson, J., Phillips, T., and Bonney, R. (2007). Citizen science as a tool for conservation in residential ecosystems. Ecol. Soc. 12, 1-11.

Couturier, L., Jaine, F., and Kashiwagi, T. (2015). First photographic records of the giant manta ray Manta birostris off eastern Australia. PeerJ 3:e742. doi: $10.7717 /$ peerj. 742
Danielsen, F., Burgess, N. D., and Balmford, A. (2005). Monitoring matters: examining the potential of locally-based approaches. Biodivers. Conserv. 14, 2507-2542. doi: 10.1007/s10531-005-8375-0

Danielsen, F., Burgess, N. D., Jensen, P. M., and Pirhofer-Walzl, K. (2010). Environmental monitoring: the scale and speed of implementation varies according to the degree of peoples involvement. J. Appl. Ecol. 47, 1166-1168. doi: 10.1111/j.1365-2664.2010.01874.x

de Andrade, A. B., and de Oliveira Soares, M. (2017). Offshore marine protected areas: divergent perceptions of divers and artisanal fishers. Mar. Policy 76, 107-113. doi: 10.1016/j.marpol.2016.11.016

de Juan, S., Gelcich, S., and Fernandez, M. (2017). Integrating stakeholder perceptions and preferences on ecosystem services in the management of coastal areas. Ocean Coast. Manag. 136, 38-48. doi: 10.1016/j.ocecoaman.2016. 11.019

Dearden, P., Bennett, M., and Rollins, R. (2006). Implications for coral reef conservation of diver specialization. Environ. Conserv. 33, 353-363.

Delaney, D. G., Sperling, C. D., Adams, C. S., and Leung, B. (2008). Marine invasive species: validation of citizen science and implications for national monitoring networks. Biol. Invasions 10, 117-128. doi: 10.1007/s10530-007-9114-0

Dickinson, J. L., Shirk, J., Bonter, D., Bonney, R., Crain, R. L., Martin, J., et al. (2012). The current state of citizen science as a tool for ecological research and public engagement. Front. Ecol. Environ. 10:291-297. doi: 10.1890/110236

Dimmock, K. (2009). Finding comfort in adventure: experiences of recreational SCUBA divers. Leis. Stud. 28, 279-295. doi: 10.1080/02614360902951674

Drew, J. A. (2005). Use of traditional ecological knowledge in marine conservation. Conserv. Biol. 19, 1286-1293. doi: 10.1111/j.1523-1739.2005.00158.x

Dytham, C. (2003). Choosing and Using Statistics a Biologist's Guide. Hoboken, NJ: Blackwell Science.

Edgar, G. J., and Stuart-Smith, R. D. (2009). Ecological effects of marine protected areas on rocky reef communities - a continental-scale analysis. Mar. Ecol. Prog. Ser. 388, 51-62. doi: 10.3354/meps08149

Edgar, G. J., and Stuart-Smith, R. D. (2014). Systematic global assessment of reef fish communities by the reef life survey program. Sci. Data 1, 1-8. doi: 10.1038/ sdata. 2014.7

Edgar, G. J., Stuart-Smith, R. D., Willis, T. J., Kininmonth, S., Baker, S. C., Banks, S., et al. (2014). Global conservation outcomes depend on marine protected areas with five key features. Nature 506, 216-220. doi: 10.1038/nature13022

Edney, J. (2012). Diver characteristics, motivations, and attitudes: Chuuk Lagoon. Tour. Mar. Environ. 8, 7-18. doi: 10.3727/154427312x13262430523983

Field, A. P. (2013). Discovering Statistics Using IBM SPSS Statistics and Sex and Drugs and Rock ' $n$ ' Roll, 4th Edn. Thousand Oaks, CA: Sage.

Fourcade, Y. (2016). Comparing species distributions modelled from occurrence data and from expert-based range maps. Implication for predicting range shifts with climate change. Ecol. Inform. 36, 8-14. doi: 10.1016/j.ecoinf.2016.09.002

Franzoni, C., and Sauermann, H. (2014). Crowd science: the organization of scientific research in open collaborative projects. Res. Policy 43, 1-20. doi: 10.1016/j.respol.2013.07.005

Freitag, A., Meyer, R., and Whiteman, L. (2016). Strategies employed by citizen science programs to increase the credibility of their data. Citiz. Sci. Theory Pract. $1,1-11$.

Freiwald, J., Meyer, R., Caselle, J., Blanchette, C. A., Hovel, K., Neilson, D., et al. (2018). Citizen science monitoring of marine protected areas: case studies and recommendations for integration into monitoring programs. Mar. Ecol. 39:46.

Gallardo, G. L., Stotz, W., Aburto, J., Mondaca, C., and Vera, K. (2011). Emerging commons within artisanal fisheries. The chilean territorial use rights in fisheries (TURFs) within a broader coastal landscape. Int. J. Commons 5, 459-484.

Godoy, N., Gelcich, S., Castilla, J. C., Lima, M., and Smith, A. (2016). Artisanal spearfishery in temperate nearshore ecosystems of Chile: exploring the catch composition, revenue, and management needs. Mar. Coast. Fish. 8, 436-447. doi: 10.1080/19425120.2016.1185062

Godoy, N., Gelcich, S., Vásuqez, J. A., and Castilla, J. C. (2010). Spearfishing to depletion: evidence from temperate reef fishes in Chile. Ecol. Appl. 20, 1504-1511. doi: 10.1890/09-1806.1

Grant, S., and Berkes, F. (2007). Fisher knowledge as expert system: a case from the longline fishery of Grenada, the Eastern Caribbean. Fish. Res. 84, 162-170. doi: 10.1016/j.fishres.2006.10.012 
Hammerton, Z. (2017). Determining the variables that influence SCUBA diving impacts in eastern Australian marine parks. Ocean Coast. Manag. 142, 209-217. doi: 10.1016/j.ocecoaman.2017.03.030

Hattam, C. E., Mangi, S. C., Gall, S. C., and Rodwell, L. D. (2014). Social impacts of a temperate fisheries closure: understanding stakeholders' views. Mar. Policy 45, 269-278. doi: 10.1016/j.marpol.2013.09.005

Huveneers, C., Luo, K., Otway, N. M., and Harcourt, R. G. (2009). Assessing the distribution and relative abundance of wobbegong sharks (Orectolobidae) in New South Wales, Australia, using recreational SCUBA-divers. Aquat. Living Resour. 22, 255-264. doi: 10.1051/alr/2009046

Jacobs, C., and Zipf, A. (2017). Completeness of citizen science biodiversity data from a volunteered geographic information perspective. Geo-Spatial Inf. Sci. 20, 3-13. doi: 10.1080/10095020.2017.1288424

Johnson, A. E., and Jackson, J. B. C. (2015). Fisher and diver perceptions of coral reef degradation and implications for sustainable management. Glob. Ecol. Conserv. 3, 890-899. doi: 10.1016/j.gecco.2015.04.004

Kirkbride-Smith, A. E., Wheeler, P. M., and Johnson, M. L. (2013). The relationship between diver experience levels and perceptions of attractiveness of artificial reefs - Examination of a potential management tool. PLoS One 8:e68899. doi: 10.1371/journal.pone.0068899

Le Fur, J., Guilavogui, A., Teitelbaum, A., and Rochet, M.-J. (2011). Contribution of local fishermen to improving knowledge of the marine ecosystem and resources in the Republic of Guinea, West Africa. Can. J. Fish. Aquat. Sci. 68, 1454-1469. doi: 10.1139/f2011-061

Lucrezi, S., Milanese, M., Palma, M., and Cerrano, C. (2018). Stirring the strategic direction of SCUBA diving marine Citizen Science: a survey of active and potential participants. PLoS One 13:e0202484. doi: 10.1371/journal.pone. 0202484

Lucrezi, S., Saayman, M., and van der Merwe, P. (2013). Managing diving impacts on reef ecosystems: analysis of putative influences of motivations, marine life preferences and experience on divers' environmental perceptions. Ocean Coast. Manag. 76, 52-63. doi: 10.1016/j.ocecoaman.2013.02.020

MacCarthy, M., O’Neill, M., and Williams, P. (2006). Customer satisfaction and SCUBA-diving: some insights from the deep. Serv. Ind. J. 26, 537-555. doi: 10.1080/0264206060072 2841

Macdonald, P., Angus, C. H., Cleasby, I. R., and Marshall, C. T. (2014). Fishers' knowledge as an indicator of spatial and temporal trends in abundance of commercial fish species: megrim (Lepidorhombus whiffiagonis) in the northern North Sea. Mar. Policy 45, 228-239. doi: 10.1016/j.marpol.2013.1 1.001

Maney, E. J. Jr., and Genovese, S. J. (2000). Scientific diver training at Northeastern University. Mar. Technol. Soc. J. 34, 38-46. doi: 10.1371/journal.pone.016 3190

Martin, V. Y. (2017). Citizen Science as a means for increasing engagement in science. Sci. Commun. 39:107554701769616. doi: 10.1177/107554701769 6165

Martin, V. Y., Christidis, L., Lloyd, D. J., and Pecl, G. T. (2016a). Understanding drivers, barriers and information sources for public participation in marine citizen science. J. Sci. Commun. 15, 1-19.

Martin, V. Y., Christidis, L., and Pecl, G. T. (2016b). Public interest in marine citizen science: is there potential for growth? Bioscience 66, 683-692. doi: 10.1093/biosci/biw070

McKinley, D. C., Miller-Rushing, A. J., Ballard, H. L., Bonney, R., Brown, H., CookPatton, S. C., et al. (2017). Citizen science can improve conservation science, natural resource management, and environmental protection. Biol. Conserv. 208, 15-28.

McKinley, D. C., Miller-Rushing, A. J., Ballard, H. L., Bonney, R., Brown, H., Evans, D. M., et al. (2015). Investing in citizen science can improve natural resource management and environmental protection. Issu. Ecol. $19,1-27$.

Measham, T. G., and Barnett, G. B. (2008). Environmental volunteering: motivations, modes and outcomes. Aust. Geogr. 39, 537-552. doi: 10.1523/ JNEUROSCI.3255-16.2017

Mundet, L., and Ribera, L. (2001). Characteristics of divers at a Spanish resort. Tour. Manag. 22, 501-510. doi: 10.1016/s0261-5177(01)00 016-4
Musa, G., Kadir, S. L. S. A., and Lee, L. (2006). Layang Layang: an empirical study on SCUBA divers' satisfaction. Tour. Mar. Environ. 2, 89-102. doi: 10.3727/ 154427306779436273

Obura, D. O. (2001). Participatory monitoring of shallow tropical marine fisheries by artisanal fisheries in Diani, Kenya. Bull. Mar. Sci. 69, 777-791.

Obura, D. O., Wells, S., Church, J., and Horrill, C. (2002). Monitoring of fish and fish catches by local fishermen in Kenya and Tanzania. Mar. Freshw. Res. 53, 215-222.

Pecl, G., Barry, Y., Brown, R., Frusher, S., Gärtner, E., Pender, A., et al. (2014). Redmap?: ecological monitoring and community engagement through citizen science. Tasmanian Nat. 136, 158-164.

Price, C. A., and Lee, H. S. (2013). Changes in participants' scientific attitudes and epistemological beliefs during an astronomical citizen science project. J. Res. Sci. Teach. 50, 773-801. doi: 10.1002/tea.21090

Roelfsema, C., Thurstan, R., Beger, M., Dudgeon, C., Loder, J., Kovacs, E., et al. (2016). A citizen science approach: a detailed ecological assessment of subtropical reefs at Point Lookout, Australia. PLoS One 11:e0163407. doi: 10. 1371/journal.pone.0163407

RStudio Team (2016). RStudio: Integrated Development for R. Boston, MA: RStudio, Inc. Available at: http://www.rstudio.com/

Salim, N., Bahauddin, A., and Mohamed, B. (2013). Influence of SCUBA divers' specialization on their underwater behavior. Worldw. Hosp. Tour. Themes 5, 388-397. doi: 10.1108/whatt-03-20130015

Savio, L., Del Prainsack, B., and Buyx, A. (2017). Motivations of participants in the citizen science of microbiomics: data from the British Gut Project. Genet. Med. 19, 959-961. doi: 10.1038/gim.201 6.208

Schmitt, E. F., Semmens, B. X., and Sullivan, K. M. (1993). Research Applications of Volunteer Generated Coral Reef Fish Surveys. Coral Gables: The Nature Conservancy and the University of Miami, Department of Biology Report, 38.

Shirk, J. J. L., Ballard, H. H. L., Wilderman, C. C., Phillips, T., Wiggins, A., Jordan, R., et al. (2012). Public participation in scientific research: a framework for deliberate design. Ecol. Soc. 17:29.

Stang, P. R., and Wiener, E. L. (1970). Diver performance in cold water. Hum. Factors 12, 391-399. doi: 10.1177/001872087001200405

Stephenson, R. L., Stacey, P., Pastoors, M. A., Marloes, K., Petter, H., Melanie, W., et al. (2016). Integrating fishers' knowledge research in science and management. J. Mar. Sci. 73, 1459-1465. doi: 10.1093/icesjms/fs w025

Suazo, C. G., Schlatter, R. P., Arriagada, A. M., Cabezas, L. A., and Ojeda, J. (2013). Fishermen's perceptions of interactions between seabirds and artisanal fisheries in the Chonos archipelago, Chilean Patagonia. Oryx 47, 184-189. doi: $10.1017 / \mathrm{s} 0030605311001815$

Terrón-Sigler, A., León-Muez, D., Peñalver-Duque, P., and Torre, F. E. (2016). The effects of SCUBA diving on the endemic Mediterranean coral Astroides calycularis. Ocean Coast. Manag. 122, 1-8. doi: 10.1016/j.ocecoaman.2016.01. 002

Tessier, A., Dalias, N., and Lenfant, P. (2015). Expectation of professional and recreational users of artificial reefs in the Gulf of Lion, France. J. Appl. Ichthyol. 31, 60-73. doi: 10.1111/jai.12951

Thapa, B., Graefe, A. R., and Meyer, L. A. (2005). Moderator and mediator effects of SCUBA diving specialization on marine-based environmental knowledgebehavior contingency. J. Environ. Educ. 37, 53-67. doi: 10.3200/joee.37.1. 53-68

Theberge, M. M., and Dearden, P. (2006). Detecting a decline in whale shark Rhincodon typus sightings in the Andaman Sea, Thailand, using ecotourist operator-collected data. Oryx 40, 337-342.

Thiel, M., Macaya, E. C., Acuña, E., Arntz, W. E., Bastias, H., Brokordt, K., et al. (2007). The Humboldt current system of northern and central Chile: oceanographic processes, ecological interactions and socioeconomic feedback. Oceanogr. Mar. Biol. Annu. Rev 45, 195-344. doi: 10.1201/978142005094 3.ch6

Thiel, M., Penna-Díaz, M. A., Luna-Jorquera, G., Salas, S., Sellanes, J., and Stotz, W. (2014). Citizen scientists and marine research: volunteer participants, their contributions, and projection for the future. Oceanogr. Mar. Biol. Annu. Rev. 52, 257-314. doi: 10.1201/b17143-6 
Todd, S. L., Cooper, T., and Graefe, A. R. (2000). "SCUBA diving \& underwater cultural resources: differences in environmental beliefs, ascriptions of responsability, and management preferences based on level of development," in Proceedings of the 2000 Northeastem Recreation Research Symposium, (Radnor, PA: US Forest Service, North- eastern Forest Experiment Station), 131-140.

Tulloch, A. I. T., Possingham, H. P., Joseph, L. N., Szabo, J., and Martin, T. G. (2013). Realising the full potential of citizen science monitoring programs. Biol. Conserv. 165, 128-138. doi: 10.1016/j.biocon.2013.05.025

Vermeiren, P., Munoz, C., Zimmer, M., and Sheaves, M. (2016). Hierarchical toolbox: ensuring scientific accuracy of citizen science for tropical coastal ecosystems. Ecol. Indic. 66, 242-250. doi: 10.1016/j.ecolind.2016.01.031

Vianna, G. M. S., Meekan, M. G., Bornovski, T. H., and Meeuwig, J. J. (2014). Acoustic telemetry validates a citizen science approach for monitoring sharks on coral reefs. PLoS One 9:e0095565. doi: 10.1371/journal.pone.009 5565

Ward-Paige, C. A., Westell, A., and Sing, B. (2018). Using eOceans diver data to describe contemporary patterns of marine animal populations: a case study of sharks in Thailand. Ocean Coast. Manag. 163, 1-10. doi: 10.1016/j.ocecoaman. 2018.05.023

Watson, A. E., and Pulford, B. D. (2004). Personality differences in high risk sports amateurs and instructors. Percept. Mot. Skills 99, 83-94. doi: 10.2466/pms.99.1. 83-94

West, S., and Pateman, R. (2016). Recruiting and retaining participants in citizen science: what can be learned from the volunteering literature? Citiz. Sci. Theory Pract. 1, 1-10.
Wiener, C. S., Manset, G., and Lemus, J. D. (2016). Ocean use in Hawaii as a predictor of marine conservation interests, beliefs, and willingness to participate: an exploratory study. J. Environ. Stud. Sci. 6, 712-723. doi: 10.1007/ s13412-015-0272-6

Wolfe, J. R., and Pattengill-Semmens, C. V. (2013). Fish population fluctuation estimates based on fifteen years of reef volunteer diver data for the Monterey Peninsula, California. California Cooperative Ocean. Fish. Invest. Rep. 54, 141154.

Wright, S., Hull, T., Sivyer, D. B., Pearce, D., Pinnegar, J. K., Sayer, M. D. J., et al. (2016). SCUBA divers as oceanographic samplers: the potential of dive computers to augment aquatic temperature monitoring. Sci. Rep. 6:30164. doi: $10.1038 /$ srep30164

Young, M. A. L., Foale, S., and Bellwood, D. R. (2015). Dynamic catch trends in the history of recreational spearfishing in Australia. Conserv. Biol. 29, 784-794. doi: 10.1111/cobi.12456

Conflict of Interest Statement: The authors declare that the research was conducted in the absence of any commercial or financial relationships that could be construed as a potential conflict of interest.

Copyright (c) 2019 Hermoso, Martin, Stotz, Gelcich and Thiel. This is an open-access article distributed under the terms of the Creative Commons Attribution License (CC BY). The use, distribution or reproduction in other forums is permitted, provided the original author(s) and the copyright owner(s) are credited and that the original publication in this journal is cited, in accordance with accepted academic practice. No use, distribution or reproduction is permitted which does not comply with these terms. 